\title{
X-ray Photoelectron Spectroscopic Analysis of Modified MWCNT and Dynamic Mechanical Properties of E-beam Cured Epoxy Resins with the MWCNT
}

\author{
Young-Seak Lee ${ }^{1, \star}$, Ji Sun Im¹, Seok-Min Yun ${ }^{1}$, Young Chang Nho², Phil Hyun Kang ${ }^{2}$ \\ and Hangkyo $\mathrm{Jin}^{3}$ \\ ${ }^{1}$ Department of Nanotechnology, Chungnam National University, Daejeon 305-764, Korea \\ ${ }^{2}$ Radiation Application Research Division, Korea Atomic Energy Research Institute, Daejeon 305-600, Korea \\ ${ }^{3}$ Korea Research Institute of Chemical Technology, P.O. Box 107, Yuseong, Daejeon 305-600, Korea \\ ‘e-mail: youngslee@cnu.ac.kr \\ (Received October 19, 2009; Accepted December 11, 2009)
}

\begin{abstract}
The surface treatment effects of reinforcement filler were investigated based on the dynamic mechanical properties of mutiwalled carbon nanotubes (MWCNTs)/epoxy composites. The as-received MWCNTs(R-MWCNTs) were chemically modified by direct oxyfluorination method to improve the dispersibility and adhesiveness with epoxy resins in composite system. In order to investigate the induced functional groups on MWCNTs during oxyfluorination, X-ray photoelectron spectroscopy was used. The thermo-mechanical property of MWCNTs/epoxy composite was also measured based on effects of oxyfluorination treatment of MWCNTs. The storage modulus of MWCNTs/epoxy composite was enhanced about 1.27 times through oxyfluorination of MWCNTs fillers at $25^{\circ} \mathrm{C}$. The storage modulus of oxyfluorinated MWCNTs (OF73-MWCNTs) reinforced epoxy composite was much higher than that of R-MWCNTs/epoxy composite. It revealed that oxygen content led to the efficient carbon-fluorine covalent bonding during oxyfluorination. These functional groups on surface modified MWCNTs induced by oxyfluorination strikingly made an important role for the reinforced epoxy composite.
\end{abstract}

Keywords : Dynamic mechanical properties, Carbon nanotube, Oxyfluorination, Epoxy resin, Radiation curing

\section{Introduction}

One of promising material for the most important thermosetting polymers is the epoxy resin which is widely used as matrices in reinforced composites, adhesives in the aerospace industry and surface coatings. But they were suffered by the weak mechanical properties [1,2]. As a reinforcement filler, the carbon nanotubes (CNTs) have been drawn a worldwide interest to be used in polymer composite systems [2-5]. The properties of CNTs, such as electrical and thermal conductivities, and chemical and mechanical stabilities, can provide novel properties to polymer composite systems. Moreover, functionalization of CNTs can induce improved properties of composite system [6] and oxyfluorination is one of the effective methods for that [7-9]. Our previous work showed that the strong bond can be formed between $\mathrm{F}^{-}$ion leads and other elements due to the high electronegativity of fluorine [10].

The polymerization of epoxy monomer has been carried out generally by thermal treatment. As a recent alternative for the more simple and efficient procedure, E-beam induced polymerization is one of the main areas on which much interest has been drawn and there have been considerable developments about the E-beam cured advanced composites for the use of aerospace and other industries [11]. But, few industrial results using E-beam or Y-ray irradiation on physical properties have been reported.

In this study, the surface modification effects of MWCNTs additives were investigated based on improved mechanical properties of e-beam cured epoxy resin. The surface modification was carried out by using direct oxyfluorination method which is so simple and effective for introducing functional groups on MWCNTs surface [7-9].

\section{Experimental}

\subsection{Materials}

As an epoxy monomer, diglycidyl ether of bisphenol A (DGEBA) (YD128, viscosity: 11,500 13,500 cps, Kukdo Chemical Co., Korea) was used. Multi-walled carbon nanotubes (MWCNTs, Aldrich) and triarylsulphonium hexafluoro-phosphate (mixed, 50\% in propylene carbonate, Aldrich) were used as a reinforcement filler and photo initiator. Oxyfluorination was carried out by using fluorine 
(Messer Grieheim GmbH , 99.8\%), oxygen (99.999\%), and argon (99.999\%) gases.

\subsection{Oxyfluorination of MWCNTs}

The surface modification of the as-received MWCNT(RMWCNTs) was carried out by oxyfluorination treatment using oxyfluorination apparatus which consists of a reactor, a vacuum-pump, and a buffer-tank connected to gas cylinders. $1 \mathrm{~g}$ of MWCNTs was loaded on nickel boat in the reactor and was degassed at $473 \mathrm{~K}$ for $2 \mathrm{~h}$. Oxyfluorination treatment of MWCNTs was carried out at $373 \mathrm{~K}$ and $1 \mathrm{bar}$ for $10 \mathrm{~min}$ by using fluorine and oxygen mixture gases with three pressure ratios (oxygen: fluorine $=3: 7,5: 5$ and 7:3) $[12,13]$. Non-treated MWCNTs and oxyfluorinated MWCNTs were named as follows; R-MWCNTs, OF37-MWCNTs, OF55-MWCNTs and OF73-MWCNTs according to the oxyfluorination conditions of different mixing ratio of two gases.

\subsection{Blend preparation}

MWCNTs $(0.05 \mathrm{~g})$ were dispersed in ethanol $(100 \mathrm{~g})$ and the mixture was sonicated for $3 \mathrm{~h}$ to release the bundles of MWCNTs. Then $50 \mathrm{~g}$ of epoxy monomer was added into the mixture and stirred at $2000 \mathrm{rpm}$ for $4 \mathrm{~h}$. To remove ethanol, the mixture was kept at $80^{\circ} \mathrm{C}$ in oven for $4 \mathrm{~h}$.

\subsection{Procedure of irradiation curing}

$1 \mathrm{~g}$ of triarylsulphonium hexafluoro-phosphate was dropped into the blend and stirred at $2000 \mathrm{rpm}, 70^{\circ} \mathrm{C}$ for $4 \mathrm{~h}$. The blend was poured into a $150 \mathrm{~mm} \times 150 \mathrm{~mm} \times 2 \mathrm{~mm}$ aluminum mold. Then, the mold was located under E-beam accelerator (ELV-4, EB tech Co., Korea) (energy: $2.5 \mathrm{MeV}$, current: $7.5 \mathrm{~mA}$ ). E-beam was irradiated at a dose rate of $300 \mathrm{kGy} / \mathrm{h}$ in atmosphere. Then the E-beam cured epoxy was detached for cooling at room temperature.

\subsection{XPS analysis and DMA test}

The chemical analysis of MWCNTs was carried out by using XPS spectra (MultiLab 2000 spectrometer, Al Ka, $1485.6 \mathrm{eV}$, Thermo electron Co., England) to investigate the changes of chemical species on the surface of MWCNTs based on effects of oxyfluorination. The survey spectra within the binding energy range of $0 \sim 1200 \mathrm{eV}$, were investigated to identify the elements on the surface of MWCNTs and perform a quantitative analysis. The binding energies of all peaks were corrected by comparing with the reference peak (graphite $\mathrm{C} 1 \mathrm{~s}, 285.0 \mathrm{eV}$ ). Dynamic mechanical thermal analysis (DMA) was carried out on Ebeam cured samples by SDTA840 (TA Instrument Co., USA), equipped with a three point bending at a frequency of

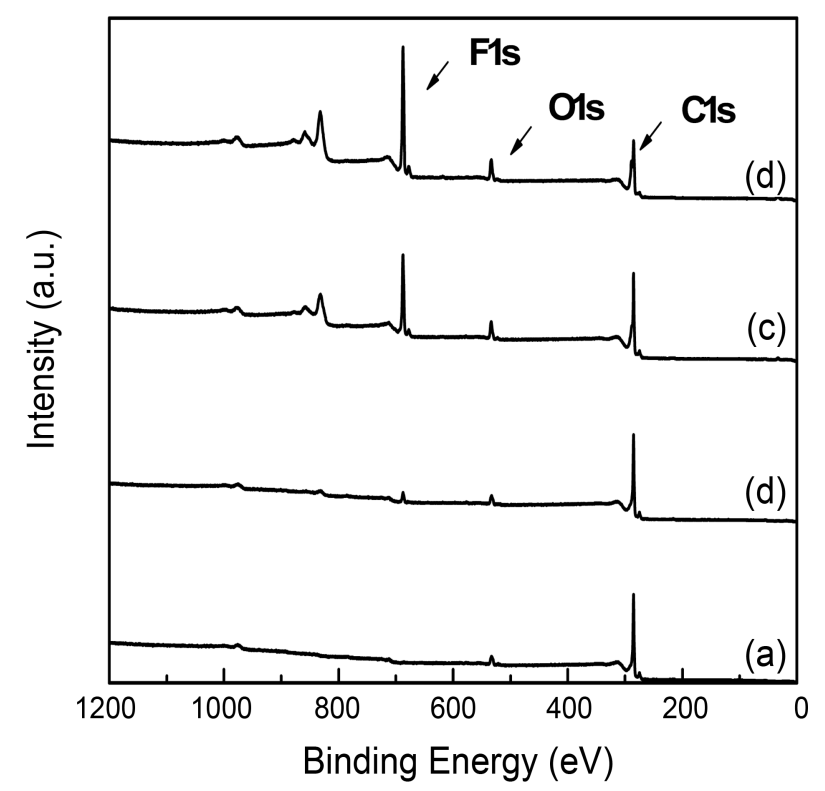

Fig. 1. XPS wide scan spectra of R-MWCNTs (a); OF37MWCNTs (b); OF55-MWCNTs (c); OF73-MWCNTs (d).

1.0 Hz. Data were collected from 25 to $170^{\circ} \mathrm{C}$ at a heating rate of $5^{\circ} \mathrm{C} / \mathrm{min}$. The storage modulus of the composites was also recorded in wide range of temperature in order to investigate the changes of mechanical properties by heat.

\section{Results and Discussion}

The XPS wide scan spectra of the MWCMTs was shown based on the effects of oxyfluorination in Fig. 1. All of the survey spectra of MWCNTs showed distinctive carbon and oxygen peaks at around $285 \mathrm{eV}$ and $533 \mathrm{eV}$, respectively. And a fluorine peak was also found around $688 \mathrm{eV}$ on oxyfluorinated MWCNTs. The atomic ratio and binding energy of each element on the surface of MWCNTs were listed in Table 1. As shown in Fig. 1 and Table 1, the surface carbon concentration of samples dramatically decreased after oxyfluorination, whereas fluorine atomic ratio of oxyfluorinated samples significantly increased. And $\mathrm{O} 1 \mathrm{~s}$ peaks of oxyfluorinated MWCNTs slightly increased with increasing oxygen partial pressure. And both $\mathrm{O} 1 \mathrm{~s}$ and F1s binding energies of oxyfluorinated MWCNTs shifted to the higher value slightly. From the results of Table 1, it is clear that oxygen content made an important role to induce the functional groups on carbon surface more effectively $[14,15]$.

The core level C1s spectra of R-MWCNTs and oxyfluorinated MWCNTs were shown in Fig. 2. The C1s peaks were investigated in the range of binding energy from 281 to $296 \mathrm{eV}$. The C1s peaks of R-MWCNTs and oxyfluorinated MWCNTs were deconvoluted to several Pseudo-Voigt functions (sum of Gaussian-Lorentzian functions) 
Table 1. XPS Surface Element Analysis Parameters of R-MWCNTs and Oxyfluorinated MWCNTs
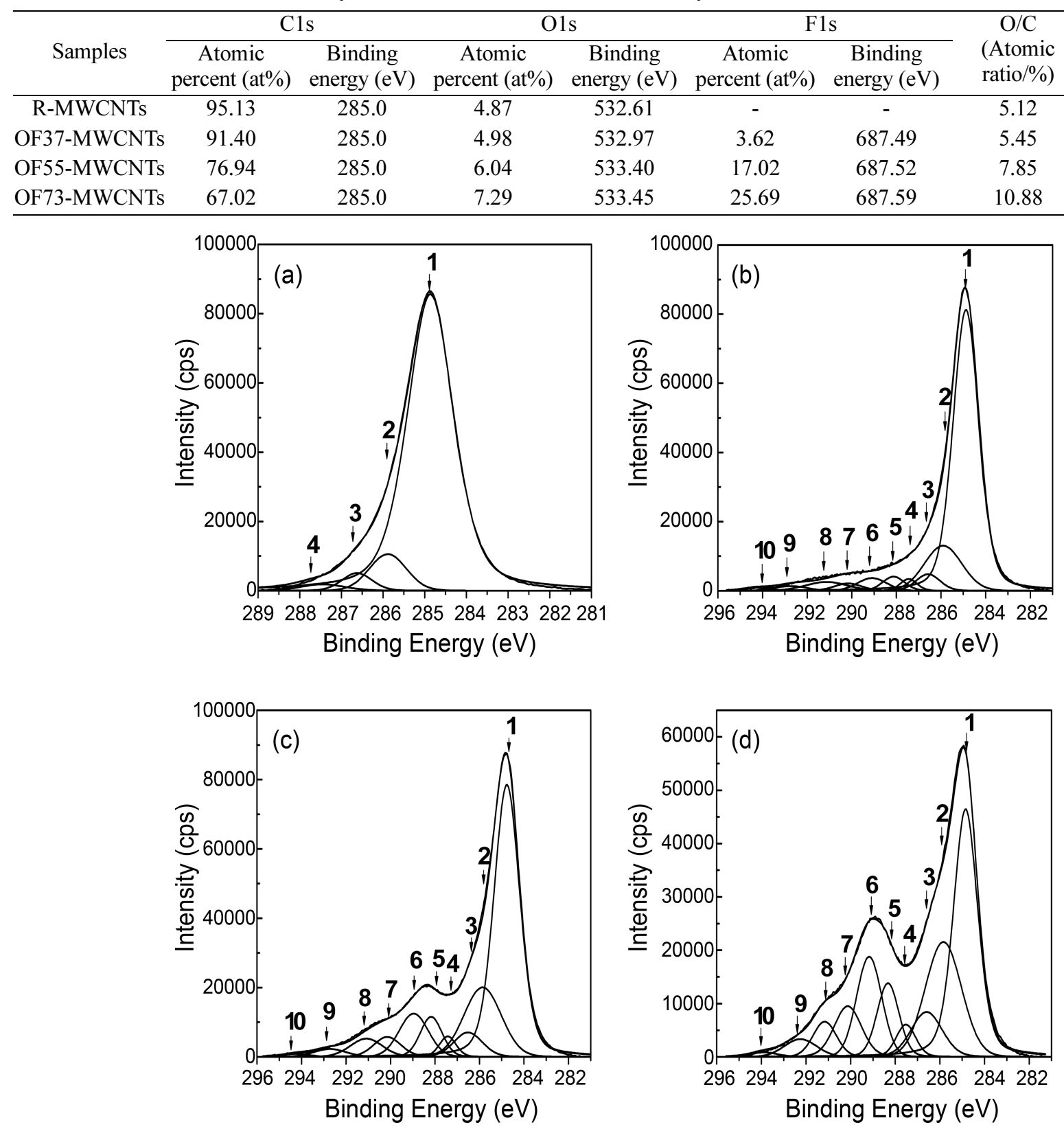

Fig. 2. Deconvolution of the core level C1s spectra: R-MWCNTs (a); OF37-MWCNTs (b); OF55-MWCNTs (c); OF73-MWCNTs (d).

by peak analysis program obtained from Unipress Co., USA. The specific assignments for the different components of $\mathrm{C} 1 \mathrm{~s}$ were listed in Table 2 in order to search the formed chemical bonds on MWCNTs during oxyfluorination. The C1s spectra of oxyfluorinated MWCNTs were fitted into 10 components in order to evaluate the components induced by oxyfluorination. The peak at lower binding energy was $\mathrm{C}(1)$ corresponding to the non-functionalized $\mathrm{sp}^{2}$ and $\mathrm{sp}^{3}$ carbon atoms. In this case, it was assumed that the $\mathrm{C}(1)$ component was $\mathrm{sp}^{2}$ carbon atoms based on the rolled graphite structure of MWCNTs. The C(1) component concentrations of samples were $88.3 \%$ (R-MWCNTs), 68.3\% (OF37-MWCNTs), 52.0\% (OF55-MWCNTs), and 34.0\% (OF73-MWCNTs). The C(6) peaks of F-MWCNTs were assigned to the carbon-fluorine covalent bond. Other $\mathrm{C} 1 \mathrm{~s}$ peaks were listed also in Table 2. $\mathrm{C}(5)$ peaks were assigned to the carbon-fluorine semi-ionic bond, which is related to the high electrical conductivity. The carbon-fluorine covalent bonding was also specified as shown from $C(6)$ to $C(10)$ in Table 2. Nansé et al. suggested the two types of carbonfluorine bonding structure by Type I and Type II of fluorinated 
Table 2. Assignments of the Different Component of C1s Spectra

\begin{tabular}{|c|c|}
\hline components & Assignment \\
\hline $\mathrm{C}(1)$ & $\begin{array}{l}\text { Non-functionalized } \mathrm{sp}^{2} \text { and } \mathrm{sp}^{3} \mathrm{C} \text { atoms, not } \\
\text { affected by fluorination }\end{array}$ \\
\hline$C(2)$ & $\begin{array}{l}\text { Aliphatic non-functionalized } \mathrm{sp}^{3} \mathrm{C} \text { in a } \\
\text { non-fluorinated environment }\end{array}$ \\
\hline$C(3)$ & $\begin{array}{l}\text { Non-functionalized } \mathrm{sp}^{2} \mathrm{C} \text { in } \beta \text { position to one } \mathrm{F} \text { atom } \\
\text { Non-functionalized } \mathrm{sp}^{2} \mathrm{C} \text { or } \mathrm{sp}^{3} \mathrm{C} \text { in } \beta \text { position to } \\
\text { one or two } \mathrm{F} \text { atom }(\mathrm{s}) \text {, respectively } \\
\mathrm{sp}^{2} \mathrm{C} \text { bound to an oxygen atom (phenol, phenyl ether) }\end{array}$ \\
\hline $\mathrm{C}(4)$ & $\begin{array}{l}\text { Non-functionalized } \mathrm{sp}^{2} \mathrm{C} \text { or } \mathrm{sp}^{3} \mathrm{C} \text { in } \beta \text { position to } \\
\text { two or three } \mathrm{F} \text { atoms, respectively } \\
\text { Oxygenated } \mathrm{sp}^{3} \mathrm{C} \text { in a non-functionalized environmen } \\
\qquad\left(\mathrm{CH}_{\mathrm{x}}-\mathrm{OH} \text {, or } \mathrm{C}-\mathrm{O}-\mathrm{C}\right)\end{array}$ \\
\hline $\mathrm{C}(5)$ & $\begin{array}{c}\text { Oxygenated } \mathrm{sp}^{3} \mathrm{C} \text { in } \beta \text { position to a } \mathrm{F} \text { atom } \\
\text { Non-functionalized } \mathrm{sp}^{3} \mathrm{C} \text { in } \beta \text { position } \\
\text { to at least three } \mathrm{F} \text { atoms } \\
\mathrm{sp}^{2} \mathrm{C} \text { 'semi-ionic', bound to intercalated } \mathrm{F} \text { atom }\end{array}$ \\
\hline$C(6)$ & $\mathrm{sp}^{2} \mathrm{C}$ covalently linked to an $\mathrm{F}$ atom in Type I structure \\
\hline$C(7)$ & $\begin{array}{l}\text { CF groups of Type I structure in } \beta \text { position } \\
\text { of } \mathrm{CF}_{2} \text { groups }\end{array}$ \\
\hline $\mathrm{C}(8)$ & $\begin{array}{c}\mathrm{CF}_{2} \text { groups of Type I structure, } \mathrm{CF} \text { groups } \\
\text { of Type II structure }\end{array}$ \\
\hline$C(9)$ & $\begin{array}{c}\mathrm{CF}_{3} \text { groups of Type I structure, } \mathrm{CF}_{2} \text { groups } \\
\text { of Type II structure }\end{array}$ \\
\hline $\mathrm{C}(10)$ & $\begin{array}{l}\mathrm{CF}_{3} \text { groups of Type II structure } \\
\text { (very weak component) }\end{array}$ \\
\hline
\end{tabular}

carbon structure [15]. Type I structure was designated as a surface of oxyfluorinated carbons, indicating that the carboncarbon skeleton and the carbon-carbon length were not significantly changed comparing with the carbon structures of as-received. On the other hand, Type II structure is the oxyfluorinated carbons indicating that $\mathrm{sp}^{2}$ carbon sheets of a planar conformation were reformed to a $\mathrm{sp}^{3}$ puckered structure. The gap between binding energy of $\mathrm{C}(1)$ and binding energies of other components was attributed to the oxyfluorination degree. The detail results of each carbon component were listed in Table 3. Under the consideration of the results of Table 3, it is sure that the surface carbon structure of MWCNTs was reformed to $\mathrm{sp}^{3}$ structure after oxyfluorination indicating that some of aromatic ring were cracked.

In order to specify the induced fluorine on MWCNTs, the F1s core level spectra of oxyfluorinated MWCNTs were presented in Fig. 3. The F1s main component of all samples was $\mathrm{F}(5)$ located around $686.74 \mathrm{eV}$. This peak was attributed to semi-ionic bound fluorine which was intercalated $\mathrm{sp}^{2}$ structured carbons [16]. Component F(4) was corresponded to the adsorbed or entrapped fluorine. As shown in Table 4, $\mathrm{F}(4)$ concentrations decreased as oxygen mixing ratio increased. Covalently bonded fluorine atoms are attributed to $\mathrm{F}(6)$ and $\mathrm{F}(7)$. Among these components, $\mathrm{F}(6)$ and $\mathrm{F}(7)$ were Type I structure. Especially, F(6), located around $687.72 \mathrm{eV}$, was corresponding to $C(6)$. The gap between $F(6)$ and $F(7)$ was about $0.9 \mathrm{eV}$. This phenomenon was come out by the charging effect of fluorine atoms. Perfluorinated carbonfluorine bonding, Type II structures were located around $689.53 \mathrm{eV}$ and $691.01 \mathrm{eV}$, corresponding to $\mathrm{F}(8)$ and $\mathrm{F}(9)$, respectively. The assignments of each component were listed in Table $5[7,15,17]$. OF73-MWCNTs showed the most carbon-fluorine covalent bonding component ratio in Table 4 and 5. It was suggested that high oxygen content led to the many carbon-fluorine covalent bondings. Similar results were observed in C1s peak as shown in Table 3. The main reason was suggested that oxygen content work as a cushion to void the perfluorinated carbons due to the high activity of fluorine with carbon.

The storage modulus and $\tan \delta$ of radiation-cured epoxy

Table 3. C1s Peak Parameters of MWCNTs in this Study

\begin{tabular}{|c|c|c|c|c|c|c|c|c|}
\hline \multirow[b]{2}{*}{ Component } & \multicolumn{2}{|c|}{ R-MWCNTs } & \multicolumn{2}{|c|}{ OF37-MWCNTs } & \multicolumn{2}{|c|}{ OF55-MWCNTs } & \multicolumn{2}{|c|}{ OF73-MWCNTs } \\
\hline & $\begin{array}{c}\text { Peak } \\
\text { Position } \\
(\mathrm{eV})\end{array}$ & $\begin{array}{c}\text { Concentration } \\
(\%)\end{array}$ & $\begin{array}{c}\text { Peak } \\
\text { Position } \\
(\mathrm{eV})\end{array}$ & $\begin{array}{c}\text { Concentration } \\
(\%)\end{array}$ & $\begin{array}{c}\text { Peak } \\
\text { Position } \\
(\mathrm{eV})\end{array}$ & $\begin{array}{c}\text { Concentration } \\
(\%)\end{array}$ & $\begin{array}{c}\text { Peak } \\
\text { Position } \\
(\mathrm{eV})\end{array}$ & $\begin{array}{c}\text { Concentration } \\
(\%)\end{array}$ \\
\hline $\mathrm{C}(1)$ & 284.88 & 88.3 & 284.87 & 68.3 & 284.76 & 52.0 & 284.86 & 34.0 \\
\hline$C(2)$ & 285.86 & 7.2 & 285.93 & 14.0 & 285.83 & 16.9 & 285.83 & 20.4 \\
\hline$C(3)$ & 286.64 & 3.0 & 286.57 & 3.5 & 286.50 & 4.8 & 286.59 & 7.2 \\
\hline $\mathrm{C}(4)$ & 287.44 & 1.5 & 287.46 & 1.6 & 287.41 & 2.3 & 287.54 & 3.2 \\
\hline$C(5)$ & & & 288.15 & 2.9 & 288.16 & 6.0 & 288.34 & 8.2 \\
\hline$C(6)$ & & & 289.12 & 3.3 & 288.98 & 8.4 & 289.16 & 12.6 \\
\hline$C(7)$ & & & 290.16 & 1.5 & 290.16 & 3.5 & 290.14 & 6.9 \\
\hline$C(8)$ & & & 291.11 & 3.1 & 291.12 & 3.8 & 291.14 & 4.0 \\
\hline$C(9)$ & & & 292.72 & 1.2 & 292.73 & 1.8 & 292.23 & 2.9 \\
\hline $\mathrm{C}(10)$ & & & 294.22 & 0.6 & 294.26 & 0.5 & 293.92 & 0.6 \\
\hline
\end{tabular}



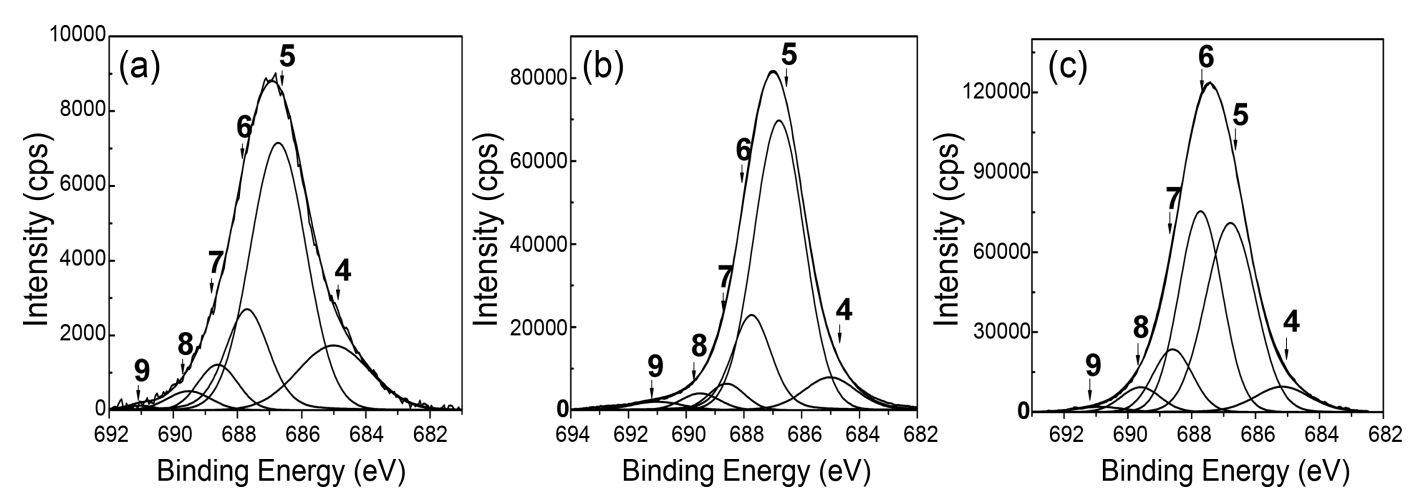

Fig. 3. Deconvolution of the core level F1s spectra; OF37-MWCNTs (a); OF55-MWCNTs (b); OF73-MWCNTs (c).

Table 4. F1s Peak Parameters of Oxyfluorinated MWCNTs

\begin{tabular}{ccccccc}
\hline Component & \multicolumn{2}{c}{ OF37-MWCNTs } & \multicolumn{2}{c}{ OF55-MWCNTs } & \multicolumn{2}{c}{ OF73-MWCNTs } \\
\cline { 2 - 7 } & $\begin{array}{c}\text { Peak Position } \\
(\mathrm{eV})\end{array}$ & $\begin{array}{c}\text { Concentration } \\
(\%)\end{array}$ & $\begin{array}{c}\text { Peak Position } \\
(\mathrm{eV})\end{array}$ & $\begin{array}{c}\text { Concentration } \\
(\%)\end{array}$ & $\begin{array}{c}\text { Peak Position } \\
(\mathrm{eV})\end{array}$ & $\begin{array}{c}\text { Concentration } \\
(\%)\end{array}$ \\
\hline $\mathrm{F}(4)$ & 685.01 & 17.2 & 685.04 & 8.0 & 685.14 & 6.4 \\
$\mathrm{~F}(5)$ & 686.74 & 54.9 & 686.80 & 64.7 & 686.78 & 40.4 \\
$\mathrm{~F}(6)$ & 687.72 & 17.8 & 687.71 & 18.3 & 687.73 & 37.2 \\
$\mathrm{~F}(7)$ & 688.64 & 6.6 & 688.59 & 4.1 & 688.62 & 10.4 \\
$\mathrm{~F}(8)$ & 689.53 & 3.1 & 689.51 & 2.8 & 689.58 & 4.3 \\
$\mathrm{~F}(9)$ & 691.01 & 0.4 & 691.04 & 2.1 & 690.90 & 1.3 \\
\hline
\end{tabular}

Table 5. Energy Shifts and Assignments of thE Different Component of F1s Spectra

\begin{tabular}{ccc}
\hline Component & $\begin{array}{c}\mathrm{F}(\mathrm{i})-\mathrm{F}(1) \\
(\mathrm{eV})\end{array}$ & Assignment \\
\hline $\mathrm{F}(4)$ & -2.6 & $\begin{array}{c}\text { Physical adsorbed and } \\
\text { entrapped fluorine }\end{array}$ \\
$\mathrm{F}(5)$ & -0.9 & $\begin{array}{c}\text { Semi-ionically bound fluorine } \\
\text { Covalent } \mathrm{CF}_{\mathrm{X}} \text { (type I structure) } \\
\text { Covalent CF1, CF2 (type I struc- } \\
\text { ture, shifted by charging) } \\
\text { Perfluorinated CF bonding } \\
\text { (type structure) }\end{array}$ \\
$\mathrm{F}(7)$ & 1.2 & $\begin{array}{c}\text { Perfluorinated CF bonding (type } \\
\text { structure, shifted by charging) }\end{array}$ \\
\hline $\mathrm{F}(8)$ & 2.0 & 3.5
\end{tabular}

composites were presented by the DMA analysis. The storage modulus of these samples indicated the amount of energy stored in the composite as elastic energy. As it was shown in Fig. 4(a), the storage modulus of oxyfluorinated MWCNTs was better than that of R-MWCNTs at $25^{\circ} \mathrm{C}$. The storage modulus of R-MWCNTs was $1.74 \mathrm{GPa}$, whereas that of OF73-MWCNTs was $2.20 \mathrm{GPa}$. Fig. 4(b) showed the glass transition temperatures $(\mathrm{Tg})$ of the composites. It was interesting to note that the maximum value of $\tan \delta$ for the neat epoxy was higher than those of the oxyfluorinated MWCNTs, comparing with the R-MWCNTs. Broad glass transition peaks and shoulders were noted from the tan $\delta$ curves of all the samples. These phenomena could be attributed to the fact that: (i) the oxyfluorinated MWCNTs promoted the cross-linking reactions of epoxy and hardener, effectively discouraging the movement of molecular chains; and (ii) the covalent bonding between the oxyfluorinated MWCNTs and epoxy promoted energy dissipation from the matrix to the MWCNTs, resulting in an increase in loss modulus [18]. The Tg of R-MWCNTs was measured as $97.7^{\circ} \mathrm{C}$ by DMA, whereas Tg of OF73-MWCNTs was measured as $116.9^{\circ} \mathrm{C}$. It tends to increase with contents of oxyfluorination. In conclusion, functional groups on surface modified MWCNTs induced by oxyfluorination might enhance the storage modulus of epoxy composites cured by E-beam irradiation for highly reinforced epoxy resin composite.

\section{Conclusions}

The surface modified MWCNTs were investigated based by XPS spectra on induced functional during oxyfluorination. The types of functional groups on MWCNTs could be different with different oxyfluorination condition. The oxygen group and fluorine group significantly increased over $50 \%$ of oxygen mixing ratio. The $\mathrm{C} 1 \mathrm{~s}$ atomic ratio of OF73-MWCNTs was 67.02 at $\%$, whereas F1s ratio was 25.69 at $\%$. This means that surface of MWCNTs was changed and reformed to carbon-fluorine structure by oxyfluorination. It suggested that high oxygen 

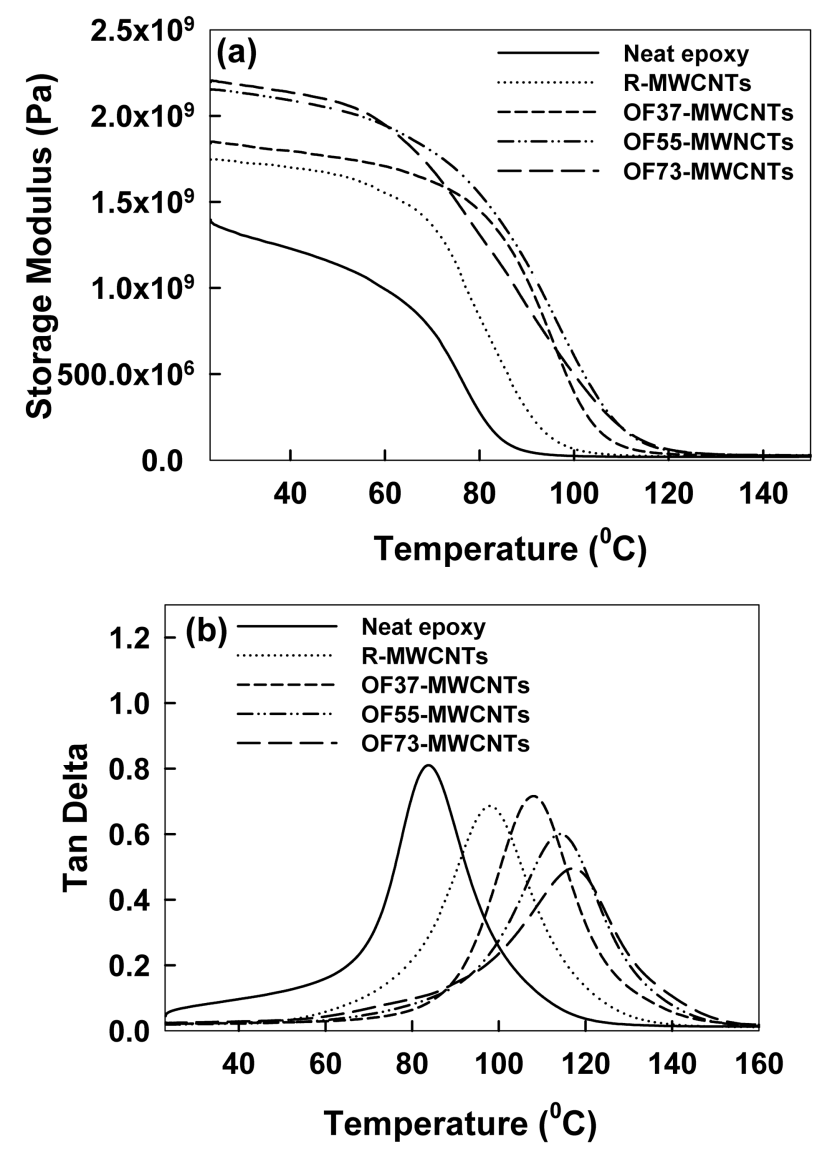

Fig. 4. Thermo-dynamic mechanical properties of oxyfluorinated MWCNTs/epoxy composites: (a) Storage Modulus and (b) Tan $\delta$ of the composites.

mixing ratio led to many carbon-fluorine covalent bonding. The DMA property of oxyfluorinated MWCNTs/epoxy composites was much better than that of R-MWCNTs/epoxy composite. It is believed that functional groups on surface modified MWCNTs induced by oxyfluorination worked for the improved attachment between MWCNTs and epoxy resin and dispersivity of MWCNTs in epoxy resin to obtain the highly reinforced epoxy resin.

\section{Acknowledgements}

This present work was supported by the Nuclear R\&D program from through the Korea Science and Engineering
Foundation funded by the Ministry of Education, Science and Technology, Korea.

\section{References}

[1] Nho, Y. C.; Kang, P. H.; Park, J. S. Radiat. Phys. Chem. 2004, 71, 241.

[2] Ogasawara, T.; Ishida, Y.; Kasai, T. Compos. Sci. Technol. 2009, 69, 2002.

[3] Prolongo, S. G..; Campo, M.; Gude, M. R.; Chaos-Morán, R.; Ureña, A. Compos. Sci. Technol. 2009, 69, 349.

[4] Kang, S.; Lee, D.; Choi, N. Compos. Sci. Technol. 2009, 69, 245.

[5] Iijima, S. Nature. 1991, 354, 56.

[6] Choi, E. S.; Brooks, J. S.; Eaton, D. L.; Al-Haik, M. S.; Hussaini, M. Y.; Garmestani, H.; Li, D.; Dahmen, K. J. App. Phys. 2003, 94, 6034.

[7] Hamwi, A.; Alvergnat, H.; Bonnamy, S.; Beguin, F. Carbon 1997, 35, 723.

[8] Tressaud, A.; Shirasaki, T.; Nanse, G.; Papirer, E. Carbon, 2002, 40, 217.

[9] Lee, Y. S.; Lee, B. K. Carbon 2002, 40, 2461.

[10] Yun, S. M.; Kim, J. W.; Jung, M. J.; Nho, Y. C.; Kang, P. H.; Lee, Y. S.; Carbon letters 2007, 8, 292.

[11] Saunders, C.; Lopata, V.; Barnard, J.; Stepanik, T. Radiat. Phys. Chem. 2000, 57, 441.

[12] Lee, Y. S.; Cho, T. H.; Lee, B. K.; Rho, J. S.; An, K. H.; Lee, Y. H. J. Fluorine Chem. 2003, 120, 99.

[13] Kim, S. D.; Kim, J. W.; Im, J. S.; Kim, Y. H.; Lee, Y. S. J. Fluorine Chem. 2007, 128, 60.

[14] Lee, J. M.; Kim, J. W.; Lim, J. S.; Kim, T. J.; Kim, S. D.; Park, S. J.; Lee, Y. S. Carbon Science 2007, 8, 120.

[15] Nanse, G.; Papirer, E.; Fioux, P.; Moguet, F.; Tressaud, A. Carbon 1997, 35, 371.

[16] Sato, Y.; Itoh, K.; Hagiwara, R.; Fukunaga, T.; Ito, Y. Carbon 2004, 42, 3243.

[17] Nanse, G.; Papirer, E.; Fioux, P.; Moguet, F.; Tressaud, A. Carbon 1997, 35, 175.

[18] Zhou, Y.; Pervin, F.; Lewis, L.; Jeelani, S. Mat. Sci. Eng. 2008, 475, 157. 